\title{
Alcohol Drinking Habits and Negative Experiences among Adolescents in Greece
}

\author{
Konstantinos Tsoumakas1, Marsela Tanaka1, Konstantinos Petsios', Georgios Fildisis, \\ Athanasios Gkoutzivelakis ${ }^{2}$, Ioanna Pavlopoulou ${ }^{1}$ \\ ${ }^{1}$ Faculty of Nursing, National and Kapodistrian University of Athens, Athens, Greece \\ ${ }^{2}$ University General Hospital of Alexandroupoli, Alexandroupoli, Greece \\ Email: mtanaka@nurs.uoa.gr
}

Received 18 June 2014; revised 15 July 2014; accepted 10 August 2014

Copyright (C) 2014 by authors and Scientific Research Publishing Inc.

This work is licensed under the Creative Commons Attribution International License (CC BY).

http://creativecommons.org/licenses/by/4.0/

(c) (i) Open Access

\begin{abstract}
Introduction: Alcohol use during adolescence remains a prominent public health problem with short- and long-term consequences. The study aims at investigating the epidemiological characteristics of alcohol use among Greek adolescents. Important parallel aims were to identify alcohol-related problems and its consequences experienced by the adolescence. Methods: The study population was a convenience sample of $\mathbf{1 1 0 0}$ students of secondary education (junior and senior high school) from 12 public and private schools in Athens. 573 boys and 527 girls aged 12 to 19 years old [mean age $15.3( \pm 1.7)]$ answered a specially structured anonymous questionnaire. Results: Recent alcohol consumption was reported by more than the half of students $(57.3 \%)$ and was more prevalent among adolescents over 15 years old $(67.3 \%)$ and among boys $(59.3 \%)$. Beer was the most popular type of alcoholic beverage $(65.9 \%)$ at all ages. On average, both males and females stated the onset of alcohol at the age of 12 years. Boys reported being drunk more often than girls (25.7\% versus $14.9 \%)$. However, more girls reported being drunk at least once a year than boys $(27.1 \%$ versus $17.6 \%)$. The vast majority of the participants stated that they were informed about the possible addiction to alcohol $(86.2 \%)$ and its negative consequences. A statistically significant correlation was found between age and hangover $(p<0.001)$. Conclusion: Alcohol consumption remains a serious problem among adolescents. There is a need to implement preventive measures and counseling approaches in school. The study will contribute to the public awareness concerning adolescent's drinking behavior in Greece.
\end{abstract}

\section{Keywords}

Adolescents, Alcohol, Epidemiology, Characteristics, Consequences

How to cite this paper: Tsoumakas, K., Tanaka, M., Petsios, K., Fildisis, G., Gkoutzivelakis, A. and Pavlopoulou, I. (2014) Alcohol Drinking Habits and Negative Experiences among Adolescents in Greece. Open Journal of Pediatrics, 4, $222-230$. 


\section{Introduction}

Adolescents' alcohol consumption is an international phenomenon, related to the health and welfare of population that has shown a small but continuous increase during the last decade and is associated with many health risks and social problems [1]-[3]. Alcohol still remains the most widely used substance among adolescents [4]-[7], exceeding the use of tobacco and illicit drugs. However, alcohol consumption and its consequences may differ significantly between countries [1] [8]. European Union (EU) is the region with the highest alcohol consumption in the world, since $87 \%$ of the European adolescents have drunk alcohol at least once during their lifetime, in addition to $70.8 \%$ of the American adolescents [3] [9] [10].

A number of recent studies have linked early alcohol use to various problems, not only due to the immediate consequences of intoxication and its possible somatic complications, but also due to long-term developmental and well-being consequences [1] [11]-[13]. Even low consumption is associated with greater risk for accidents and injuries, violent behavior, use of psychotropic drugs, tobacco use and risky behavior including unsafe sex [13]-[17]. Literature suggests three types of influence on adolescent alcohol use: social (parental characteristics, family model, parenting style and parental status), attitudinal (culture, general values, media influence, school environment and peers' drinking habits) and intrapersonal (personal traits, biological dispositions and emotional instability) [18]-[20]. Younger age at initiation of alcohol use and younger age at first intoxication are strong predictors of later alcohol abuse and are associated with higher risk of alcohol-related injuries [21]-[23]. Moreover, adolescence is the period when lifestyles and habits develop and future attitudes are established [24]. Interestingly, the age of first alcohol consumption has decreased during last decade in both genders [25].

Levels of alcohol use change over time, only studies that compare the adolescents of different ages at a single point in time can assess age and trends. According to a recent report of the European School Survey Project on Alcohol and Other Drugs (ESPAD), Greece holds one of the highest rates concerning adolescents' alcohol use among other European countries [26].

The main aim of this study was to investigate the epidemiological characteristics of alcohol use among Greek adolescents. Important parallel aims were to identify alcohol-related problems and its consequences experienced by the adolescence.

\section{Methodology}

The study population was a convenience sample of 1100 students of secondary education (junior and senior high school) from public and private schools in Athens. The sample was selected from 5 representative geographical area of Attica. In particular, we randomly selected 10 public and two private schools from official list of schools. The study was approved by the Committee on Health Promotion of the Ministry of National Education and Religions. Parents were informed by a letter sent in advance of the survey, asked to give consent for researchers to contact their children, and then the students provided verbal assent. Confidentiality and anonymity were assured.

\subsection{Data Collection}

Data collection was performed via a 20-item structured, multiple-choice questionnaire. This was the main tool for our study and was constructed based on literature and authors' clinical expertise. More specifically, the questionnaire included questions concerning alcohol consumption habits, high-risk drinking, drunkenness, experienced alcohol-related problems, negative consequences that had experienced after or under alcohol use, along with questions concerning parental smoking and drinking habits as well as supplementary socio-demographic data. Moreover, a pilot test was performed in a sample from two public schools in advance of the study.

The questionnaires were distributed during the school year 2010-2011, with the knowledge and support of the responsible officers of the schools and distributed in each classroom by a member of the research team. The forms were handed to each student, were asked to complete them in 20 - 25 minutes and to return them. Teachers were allowed to stay in the classroom during the completion of the form. To preserve a rigorously anonymous management of the data, while keeping the link with individual information collected on subsequent surveys, the questionnaires were labeled with an 8-digit individual code generated by the student.

\subsection{Statistics}

Absolute and relative frequencies were used to describe qualitative variables. The average values (mean) and standard deviations (SD) were used to describe quantitative variables. The proportions were compared using the 
chi-square $(\times 2)$ test or Fisher's exact test. The Benforri correction was used to control the Type I error and the significance level was set at $0.05 / \mathrm{k}(\mathrm{k}=$ number of comparisons). Adjusted odds ratios (OR) $95 \%$ confidence intervals (95\% CI) were computed from the results of the logistic regression analyses. For the analysis, the statistical software SPSS was used (Version 17.0).

\subsection{Glossary}

1) Recent alcohol consumption: Drinking alcohol at least once during the past 30 days before the study; 2) Systematic or regular drinking: 6 - 35 times during the past 30 days before the study; 3) Early alcohol use: Drinking alcohol before the age of 12 years old; 4) Lifetime alcohol use: Drinking alcohol at least once during their lifetime; 5) Heavy episodic drinking: Having five or more drinks on one occasion.

\section{Results}

A total of 1100 students (573 boys and 527 girls) from private and public schools with a mean age of $15.3( \pm 1.7)$ participated the study. On average, both males and females stated onset of alcohol at the age of 12 years old. 239 boys (41.7\%) and 108 girls (20.4\%) reported systematic drinking. A total of 97 (13.7\%) reported intoxication during the past 30 days. The mean age of the parents was 43.2 years and more than the half were highly educated (49.7\% of mothers and $52.8 \%$ of fathers). Systematic use of alcohol (20.6\% - 36.6\%) was stated by both parents along with active smoking (39.3\% - 49.3\%). Recent alcohol consumption was reported by more than the half of students (57.3\%). It was more prevalent among students over 15 years old (67.3\%) and among boys than girls (59.3\% versus 55.4\%). Beer was the most popular type of alcoholic beverage (65.9\%) consumed among all age groups followed by wine (61.3\%) and spirits (49.5\%), with a statistical significant prevalence especially in adolescents over 15 years old.

The participants stated their preference to drink with friends at home (29.3\%), during parties (34.3\%) or in night clubs (30.0\%), rather than alone (6.4\%). In addition, pleasure was the main reason for drinking alcohol (79.1\%), whereas sensation/novelty seeking (9.9\%), peers impression (4.3\%) or drinking as a coping strategy for emotional or family problems (6.7\%), were less frequent reasons for alcohol use.

Among drinkers, $21.8 \%$ reported being drunk at least once during the past year prior to the study, $13.7 \%$ during the past 30 days prior to the study, and $5.9 \%$ of them more than once a week prior to the study. More boys than girls (25.7\% versus 14.9\%) reported being drunk once in two months or more often. By contrast, more girls than boys (27.1\% versus $17.6 \%$ ) reported being drunk at least once a year. The association between recent alcohol consumption, type of alcohol and frequency of drunkenness with age and sex is presented in Table 1 and Table 2.

\section{Table 1. Alcohol consumption among different age groups.}

\begin{tabular}{|c|c|c|c|c|c|c|c|c|}
\hline \multirow{3}{*}{ Alcohol Use Parameters } & & \multicolumn{6}{|c|}{ Age (yrs) } & \multirow{3}{*}{$\begin{array}{c}\mathrm{p} \\
\text { chi-square } \\
\left(\chi^{2}\right) \text { test }\end{array}$} \\
\hline & & \multicolumn{2}{|c|}{$12-13$} & \multicolumn{2}{|c|}{$14-15$} & \multicolumn{2}{|c|}{$>15$} & \\
\hline & & $\mathrm{N}$ & $\%$ & $\mathrm{~N}$ & $\%$ & $\mathrm{~N}$ & $\%$ & \\
\hline \multirow{2}{*}{ Recent $^{1}$ alcohol use } & No & 107 & 69.5 & 128 & 45.2 & 159 & 32.7 & \multirow{2}{*}{$<0.001$} \\
\hline & Yes & 47 & 30.5 & 155 & 54.8 & 327 & 67.3 & \\
\hline \multirow{2}{*}{$\begin{array}{l}\text { Beer consumption during } \\
\text { the past year }\end{array}$} & None or 1 - 3 times a year & 156 & 76.8 & 205 & 59.2 & 253 & 45.9 & \multirow{2}{*}{$<0.001$} \\
\hline & $>1$ - 3 times a year & 47 & 23.2 & 141 & 40.8 & 298 & 54.1 & \\
\hline \multirow{2}{*}{$\begin{array}{l}\text { Wine consumption during } \\
\text { the past year }\end{array}$} & 1 - 3 times a year & 147 & 72.4 & 212 & 61.3 & 265 & 48.1 & \multirow{2}{*}{$<0.001$} \\
\hline & $>1$ - 3 times a year & 56 & 27.6 & 134 & 38.7 & 286 & 51.9 & \\
\hline \multirow{2}{*}{$\begin{array}{l}\text { Spirits consumption } \\
\text { during the past year }\end{array}$} & 1 - 3 times a year & 169 & 83.3 & 259 & 74.9 & 284 & 51.5 & \multirow{2}{*}{$<0.001$} \\
\hline & $>1$ - 3 times a year & 34 & 16.7 & 87 & 25.1 & 267 & 48.5 & \\
\hline \multirow{3}{*}{$\begin{array}{l}\text { Drunkenness incident } \\
\text { during the past year }\end{array}$} & No & 31 & 86.1 & 97 & 61.0 & 203 & 53.0 & \multirow{3}{*}{0.001} \\
\hline & One time in two months or more frequently & 3 & 8.3 & 35 & 22.0 & 83 & 21.7 & \\
\hline & One time a year & 2 & 5.6 & 27 & 17.0 & 97 & 25.3 & \\
\hline
\end{tabular}

${ }^{1}$ During the month prior to the study. 
Table 2. Alcohol consumption and gender.

\begin{tabular}{|c|c|c|c|c|c|c|}
\hline \multirow{3}{*}{$\begin{array}{c}\text { Alcohol Use } \\
\text { Parameters }\end{array}$} & & \multicolumn{4}{|c|}{ Gender } & \multirow{3}{*}{$\begin{array}{c}\mathrm{p} \\
\text { chi-square } \\
\left(\chi^{2}\right) \text { test }\end{array}$} \\
\hline & & \multicolumn{2}{|c|}{ Boys } & \multicolumn{2}{|c|}{ Girls } & \\
\hline & & $\mathrm{N}$ & $\%$ & $\mathrm{~N}$ & $\%$ & \\
\hline \multirow{2}{*}{ Recent $^{1}$ alcohol use } & No & 187 & 40.7 & 207 & 44.6 & \multirow[t]{2}{*}{0.234} \\
\hline & Yes & 272 & 59.3 & 257 & 55.4 & \\
\hline \multirow{2}{*}{ Beer consumption during the past year } & 1 - 3 times a year & 256 & 44.7 & 358 & 67.9 & \multirow[t]{2}{*}{$<0.001$} \\
\hline & $>1-3$ times a year & 317 & 55.3 & 169 & 32.1 & \\
\hline \multirow{2}{*}{ Wine consumption during the past year } & 1 - 3 times a year & 283 & 49.4 & 341 & 64.7 & \multirow[t]{2}{*}{$<0.001$} \\
\hline & $>1$ - 3 times a year & 290 & 50.6 & 186 & 35.3 & \\
\hline \multirow{2}{*}{ Spirits consumption during the past year } & 1 - 3 times a year & 349 & 60.9 & 363 & 68.9 & \multirow[t]{2}{*}{0.006} \\
\hline & $>1$ - 3 times a year & 224 & 39.1 & 164 & 31.1 & \\
\hline \multirow{3}{*}{ Drunkenness incident during the past year } & No & 183 & 56.7 & 148 & 58.0 & \multirow{3}{*}{0.001} \\
\hline & One time in two months or frequently & 83 & 25.7 & 38 & 14.9 & \\
\hline & One time a year & 57 & 17.6 & 69 & 27.1 & \\
\hline
\end{tabular}

${ }^{1}$ During the month prior to the study.

We applied a logistic regression model having alcohol consumption in the past month as dependent variable and the variable adolescent's gender as independent. There was found no significant difference in the likelihood of boys having consumed more alcohol than girls in the past month prior to the study (OR $=1.17,95 \%$ CI: (0.90 1.52), $\mathrm{p}=0.35$ ). Similarly, we applied a logistic regression model having the variable alcohol consumption in the past month as dependent and age as the independent. We found that 14- to 15-year-old adolescents had 2.76 times higher chance of consuming alcohol than did 12- to 13-year-old adolescents [Cl: $(1.82-4.17), \mathrm{p}<0.001$ ]. Moreover, adolescents $>15$ years had 4.68 times higher probability of consuming alcohol in the past month than those of 12- to 13-year-old adolescents [CI: (3.16 - 6.93), p < 0.001].

In our study, $24.9 \%$ of adolescents were encouraged to stop drinking, $12.7 \%$ had drunk alcohol in the morning after waking up, $15.6 \%$ had been criticized by others because of alcohol usage, and an even smaller proportion (14.1\%) had felt guilty because of alcohol use (Table 3). Moreover, a significant correlation was found between adolescents' age and driving under the influence of alcohol $(\mathrm{p}=0.035)$ (Table 4). Specifically, we found a higher prevalence of 14- to 15-year-old adolescents that drove while drunk $(\mathrm{p}=0.012)$. In addition, as age increases so does the proportion of adolescents who experience hangover $(p=0.001)$ or nausea $(p=0.05)$ after consuming alcohol (Table 4). However, the vast majority of the participants stated that they were informed about the possible addiction to alcohol (86.2\%) and the negative consequences from its consumption (85.5\%) such as hangover, nausea, vomiting etc. According to their responses, main sources of information were any member of their family (51.9\%), their friends (11.0\%) or the media (26.5\%) (TV, radio etc.).

\section{Discussion}

According to our findings the majority of the adolescents (57.3\%) stated recent alcohol consumption. Our findings are comparable to data from international studies that took place in 36 European countries in 2011 as a part of ESPAD study [9]. Recent alcohol consumption was more prevalent among older adolescents and among boys compared to girls. Comparing our results with those reported earlier we noticed a decreasing trend in alcohol consumption [27]. These findings are in line with other studies indicating a decline in alcohol consumption in many countries with previously high alcohol consumption, particularly in the traditional wine-producing and wine-drinking countries in Europe [28] [29]. According to Simons-Morton et al, this decrease is a result of the anti alcohol marketing and targeted country-level policies [29]. Therefore, strategies targeted to youth and also to entire population should be implemented.

Consistent with prior research, we found that rates of adolescent alcohol use increases with age [5] [9] [26] [30] [31]. Specifically, as age increases, so does the prevalence of adolescents having drunk alcohol during the 
Table 3. Experienced problems caused due to alcohol consumption among different age groups.

\begin{tabular}{|c|c|c|c|c|c|c|c|c|}
\hline \multirow{3}{*}{ Consequences } & & \multicolumn{6}{|c|}{ Age Group (yrs) } & \multirow{3}{*}{$\begin{array}{c}\mathrm{p} \\
\text { chi-square } \\
\left(\chi^{2}\right) \text { test }\end{array}$} \\
\hline & & \multicolumn{2}{|c|}{$12-13$} & \multicolumn{2}{|c|}{$14-15$} & \multicolumn{2}{|c|}{$>15$} & \\
\hline & & $\mathrm{N}$ & $\%$ & $\mathrm{~N}$ & $\%$ & $\mathrm{~N}$ & $\%$ & \\
\hline \multirow{2}{*}{ Fight } & No & 24 & 72.7 & 117 & 83.0 & 312 & 86.0 & \multirow{2}{*}{0.117} \\
\hline & Yes & 9 & 27.3 & 24 & 17.0 & 51 & 14.0 & \\
\hline \multirow{2}{*}{ Relationship problems } & No & 26 & 86.7 & 121 & 87.1 & 318 & 88.1 & \multirow{2}{*}{0.935} \\
\hline & Yes & 4 & 13.3 & 18 & 12.9 & 43 & 11.9 & \\
\hline \multirow{2}{*}{ Argue } & No & 24 & 77.4 & 109 & 77.9 & 305 & 85.0 & \multirow{2}{*}{0.125} \\
\hline & Yes & 7 & 22.6 & 31 & 22.1 & 54 & 15.0 & \\
\hline \multirow{2}{*}{ Trouble with the police } & No & 27 & 90.0 & 128 & 92.1 & 340 & 95.8 & \multirow{2}{*}{0.149} \\
\hline & Yes & 3 & 10.0 & 11 & 7.9 & 15 & 4.2 & \\
\hline \multirow{2}{*}{ Drove the car } & No & 29 & 96.7 & 125 & 86.8 & 334 & 93.3 & \multirow{2}{*}{0.035} \\
\hline & Yes & 1 & 3.3 & 19 & 13.2 & 24 & 6.7 & \\
\hline \multirow{2}{*}{ Attending class } & No & 29 & 96.7 & 117 & 81.3 & 294 & 81.0 & \multirow{2}{*}{0.097} \\
\hline & Yes & 1 & 3.3 & 27 & 18.8 & 69 & 19.0 & \\
\hline \multirow{2}{*}{ Missing class } & No & 28 & 93.3 & 122 & 84.7 & 313 & 87.2 & \multirow{2}{*}{0.425} \\
\hline & Yes & 2 & 6.7 & 22 & 15.3 & 46 & 12.8 & \\
\hline
\end{tabular}

Table 4. Negative consequences caused by alcohol consumption among different age groups.

\begin{tabular}{|c|c|c|c|c|c|c|c|c|}
\hline \multirow{3}{*}{ Consequences } & & \multicolumn{6}{|c|}{ Age Group (yrs) } & \multirow{3}{*}{$\begin{array}{c}\mathrm{p} \\
\text { chi-square } \\
\left(\chi^{2}\right) \text { test }\end{array}$} \\
\hline & & \multicolumn{2}{|c|}{$12-13$} & \multicolumn{2}{|c|}{$14-15$} & \multicolumn{2}{|c|}{$>15$} & \\
\hline & & $\mathrm{N}$ & $\%$ & $\mathrm{~N}$ & $\%$ & $\mathrm{~N}$ & $\%$ & \\
\hline \multirow{2}{*}{ Hangover } & No & 20 & 55.6 & 62 & 41.1 & 105 & 28.7 & \multirow{2}{*}{$<0.001$} \\
\hline & Yes & 16 & 44.4 & 89 & 58.9 & 261 & 71.3 & \\
\hline \multirow{2}{*}{ Nausea/vomiting } & No & 29 & 82.9 & 97 & 69.8 & 223 & 63.9 & \multirow{2}{*}{0.050} \\
\hline & Yes & 6 & 17.1 & 42 & 30.2 & 126 & 36.1 & \\
\hline \multirow{2}{*}{ Lack of energy } & No & 24 & 70.6 & 86 & 59.7 & 218 & 61.9 & \multirow{2}{*}{0.502} \\
\hline & Yes & 10 & 29.4 & 58 & 40.3 & 134 & 38.1 & \\
\hline \multirow{2}{*}{ Fatigue/weakness } & No & 24 & 70.6 & 86 & 60.1 & 190 & 53.2 & \multirow{2}{*}{0.080} \\
\hline & Yes & 10 & 29.4 & 57 & 39.9 & 167 & 46.8 & \\
\hline \multirow{2}{*}{ Insomnia } & No & 28 & 82.4 & 108 & 75.5 & 238 & 68.2 & \multirow{2}{*}{0.087} \\
\hline & Yes & 6 & 17.6 & 35 & 24.5 & 111 & 31.8 & \\
\hline \multirow{2}{*}{ Decreased appetite } & No & 27 & 79.4 & 98 & 69.0 & 238 & 68.4 & \multirow{2}{*}{0.412} \\
\hline & Yes & 7 & 20.6 & 44 & 31.0 & 110 & 31.6 & \\
\hline \multirow{2}{*}{ Sleepy } & No & 25 & 69.4 & 93 & 66.4 & 207 & 59.1 & \multirow{2}{*}{0.201} \\
\hline & Yes & 11 & 30.6 & 47 & 33.6 & 143 & 40.9 & \\
\hline \multirow{2}{*}{ Dyspepsia/disorders stools } & No & 30 & 88.2 & 117 & 84.8 & 289 & 84.3 & \multirow{2}{*}{0.827} \\
\hline & Yes & 4 & 11.8 & 21 & 15.2 & 54 & 15.7 & \\
\hline \multirow{2}{*}{ Chills } & No & 28 & 82.4 & 119 & 85.6 & 278 & 80.8 & \multirow{2}{*}{0.459} \\
\hline & Yes & 6 & 17.6 & 20 & 14.4 & 66 & 19.2 & \\
\hline \multirow{2}{*}{ Tachycardia } & No & 29 & 85.3 & 115 & 82.7 & 286 & 83.4 & \multirow{2}{*}{0.937} \\
\hline & Yes & 5 & 14.7 & 24 & 17.3 & 57 & 16.6 & \\
\hline \multirow{2}{*}{ Sweating } & No & 29 & 82.9 & 121 & 87.1 & 280 & 81.4 & \multirow{2}{*}{0.325} \\
\hline & Yes & 6 & 17.1 & 18 & 12.9 & 64 & 18.6 & \\
\hline \multirow{2}{*}{ Respiratory distress } & No & 28 & 80.0 & 125 & 90.6 & 312 & 91.0 & \multirow{2}{*}{0.115} \\
\hline & Yes & 7 & 20.0 & 13 & 9.4 & 31 & 9.0 & \\
\hline
\end{tabular}


past 30 days before the study and who got drunk at least once during the past year prior to the study.

On average, both males and females stated onset of alcohol at the age of 12 years according to our findings. Earlier age of drinking onset is strongly related to experiencing alcohol dependence during one's life [32]. According to ESPAD findings, nearly six in ten of the European students had consumed at least one glass of alcohol and $12 \%$ had been drunk at the age of 13 or younger [9]. Tsiligianni et al. reported that $15 \%$ of elementary school students in Crete under the age of 10 had already experimented with alcohol [33]. These findings reveal once more the cultural effect, since alcohol consumption in Greece is a mean of socializing and is integrated into the ceremonial, social, and religious structures, along with the influence from the alcohol industry, since Greece is a producer and exporter of alcohol beverages. Drinking alcohol at a younger age has been associated with the three leading causes of death among youth (unintentional injury, homicide, and suicide) [6] [13]. On the other hand, close family and community relationships in Greece provide a control against overconsumption [27]. However, early alcohol onset ( $\leq 12$ years old) in Greece has not decreased despite the fact that the sale of alcoholic beverages to children under eighteen has been prohibited. This is in accordance to findings from other countries [34].

The participants stated that they prefer to drink with friends at home or out rather than alone. Therefore, our study supports the belief that alcohol consumption is related to friends' influences. Dick et al. stated that gender of friends moderate the associations between friends' behaviour and adolescents' alcohol use, with evidence that girls, and those with opposite sex friends, are more susceptible to friends' influence [35]. There might be a strong affinity among adolescents sharing the same habits and certain alcohol behaviours may be linked to the characteristics of alcohol use [36].

Beer was the most popular type of alcoholic beverage among all ages, in our study and this is in accordance to previous findings since beer is reported to be the main alcoholic beverage consumed among adolescents worldwide [25]. A possible explanation for that was that beer is much cheaper than spirits and access to beer is easier for younger adolescents [37]. Whereas, the preference for beer and spirits is more likely to be related to heavy drinking than is the preference for wine [38].

Based on the literature, there are four categories of drinking motives: Enhancement, Social, Coping, and Conformity Motives. Motives are strongly related to drinking in situations where heavy drinking is condoned (e.g. with same-sex friends, and in bars), drinking in response to pleasant emotional states, and drinking in response to urges and temptations [39]. Heavy episodic drinking is positively associated with extraversion-defined as gregariousness, sociability, and high levels of activity and excitement-seeking [40]. In our study participants stated that pleasure was the main reason for drinking alcohol. Novelty seeking, peers impression or drinking as a coping strategy for emotional or family problems, were less frequent reasons for alcohol use.

Our findings revealed a significant association between recent alcohol consumption, type of alcohol and frequency of drunkenness with age and sex. Literature has addressed gender differences in biological and psychosocial risk factors for emerging alcohol problems through the course of adolescence [41]. Similarly, the prevalence of lifetime alcohol use increases as teens get older [42]. In general, risk behaviours are often initiated during early adolescence and the frequency of engagement in behaviours rises with increasing age during the teenage years, often continuing into early adulthood [43].

Participants were randomly selected from areas with different socioeconomic status. However, there was found no correlation between the living area and frequency of alcohol intake, quantity of alcohol intake and drunkenness in our study. In the literature it's not clear whether area level is associated to adolescents drinking behaviour, since many studies have found no association [24] [44] [45].

Adolescents in our study stated a number of negative experienced problems due to alcohol consumption (Table 4). Negative criticism and feelings of guilt because of alcohol use were acknowledged by adolescents. A significant correlation was found between age and hangover. Specifically, as age increases so does the proportion of adolescents who experience hangover after consuming alcohol. This last finding is in accordance with previous studies concluding that hangover is the most usual negative consequence experienced by adolescents [9] [46].

However, a significant correlation was found between adolescents' age and driving under the influence of alcohol. This study prospectively replicates findings that early drinking onset is associated with driving under the influence of alcohol, and putting themselves in risky situations after drinking, which are strong predictors of experiencing alcohol-related injuries. Driving under alcohol influences increases the risk of a road traffic accident [23]. In Greece, according to a WHO report (2011) road death rates due to alcohol use in ages $>15$ years old was 
31.3\% for males and 7.5\% for females [47]. In the USA, 50\% of all head injuries in adolescents were associated with alcohol consumption [15].

\section{Limitations}

There are several limitations. All prevalence estimates were obtained by self-reports. Therefore, prevalence of consumption may have been underestimated as this is a stigmatizing habit. The vast majority of 12- to 19-yearold adolescents attend regular public and private schools, and therefore a greater number of participants from private schools (higher socio-economical status) may influence the results, although there was not noticed such a trend. The impact of co-consumption of tobacco and other illicit drugs in adolescent substance use were not examined in this study. Moreover, the influence of peers on adolescent substance use was not analyzed. Also, the sample was derived only from Attica and due to the huge diversity of other areas in Greece; the results should be interpreted with caution since the sample cannot represent the whole country.

\section{Conclusions}

The prevalence of recent alcohol consumption among Greek adolescents remains one of the highest in Europe (4th place, between 36 European countries) and has reached alarming prevalence [9]. Alcohol intake showed high prevalence in both genders and began at an early stage. In addition, rates of adolescent alcohol use and drunkenness increase with age, thus confirming previous studies [5] [9] [26] [30]. The persistence of adolescents' drinking problems underscores an urgent need to implement preventions and counseling approaches targeting at younger adolescents by health providers, teachers, family member and by all professionals and other people that are in contact with children. These efforts should be directed on changing drinking behaviour and on reducing risk factors for problematic drinking. Regular monitoring, effective policy measures and health education are essential in order to prevent further increases in adolescents' alcohol consumption.

Therefore, cultural sensitive interventions, addressing the cultural effect of family interaction and focusing on common risk factors with differentiated strategies for each gender, including the 11- to 15-year age group, should be implemented to prevent alcohol consumption and the adverse health and social consequences resulting from this behaviour.

\section{Acknowledgements}

The authors gratefully thank all the students and their parents who participated in the study for their valuable contribution to this study.

\section{Competing Interest}

The authors declare that they have no competing interests.

\section{References}

[1] Danielsson, A.K., Wennberg, P., Hibell, B. and Romelsjö, A. (2012) Alcohol Use, Heavy Episodic Drinking and Subsequent Problems among Adolescents in 23 European Countries: Does the Prevention Paradox Apply? Addiction, 107, 71-80. http://dx.doi.org/10.1111/j.1360-0443.2011.03537.x

[2] Visser, L., de Winter, A.F. and Reijneveld, S.A. (2012) The Parent-Child Relationship and Adolescent Alcohol Use: A Sytematic Review of Longitudinal Studies. BMC Public Health, 12, 886. http://dx.doi.org/10.1186/1471-2458-12-886

[3] WHO Regional Office for Europe (2012) Alcohol in the European Union Consumption, Harm and Policy Approaches. WHO Regional Office for Europe, Copenhagen. http://www.euro.who.int/data/\%20assets/pdf_file/0003/160680/\%20e96457.pdf

[4] Johnston, L., O’Malley, P.M., Bachman, J.G. and Schulenberg, J.E. (2011) Monitoring the Future National on Results on Adolescent Drug Use: Overview of Key Findings, 2010. Ann Arbor: Institute for Social Research, The University of Michigan. http://radar.boisestate.edu/radar/pdfs/mtf-overview 2010.pdf

[5] Johnston, L.D., O’Malley, P.M., Bachman, J.G. and Schulenberg, J.E. (2012) Monitoring the Future National Results on Adolescent Drug Use: Overview of Key Findings, 2011. Ann Arbor: Institute for Social Research, The University of Michigan. http://files.eric.ed.gov/fulltext/ED529133.pdf

[6] Department of Health and Human Services (2007) The Surgeon General's Call to Action to Prevent and Reduce Un- 
derage Drinking. Department of Health and Human Services, Office of the Surgeon General. http://www.ncbi.nlm.nih.gov/books/NBK44360/pdf/TOC.pdf

[7] American Academy of Pediatrics (2010) Policy Statement. Alcohol Use by Youth and Adolescents: A Pediatric Concern. Pediatrics, 125, 185. http://dx.doi.org/10.1542/peds.2010-0438

[8] Plant, M.A, Plant, M.L., Miller, P., Gmel, G. and Kuntsche, S. (2009) The Social Consequences of Binge Drinking: A Comparison of Young Adults in Six European Countries. Journal of Addictive Diseases, 28, 294-308. http://dx.doi.org/10.1080/10550880903182978

[9] Hibell, B., et al. (2012) The 2011 ESPAD Report-Substance Use Among Students in 36 European Countries. The Swedish Council for Information on Alcohol and other Drugs (CAN). Stockholm, Sweden. http://www.can.se/PageFiles/2619/The_2011_ESPAD_Report_FULL.pdf?epslanguage=sv

[10] Eaton, D.K., et al. (2012) Youth Risk Behavior Surveillance-United States (2011) Morbidity and Mortality Weekly Report (MMWR), 61, 1-162. http://www.cdc.gov/mmwr/preview/ mmwrhtml/ss6104a1.htm

[11] Eaton, D.K., et al. (2010) Youth Risk Behavior Surveillance-United States, 2009. Morbidity and Mortality Weekly Report (MMWR), 59, 1-142. http://www.cdc.gov/mmwr/pdf/ss/ss5905.pdf

[12] Hingson, R.W. and Winter, M. (2003) Epidemiology and Consequences of Drinking and Driving. Alcohol Research Health, 27, 63-78. http://pubs.niaaa.nih.gov/publications/arh27-1/63-78.pdf

[13] Miller, J.W., Naimi, T.S., Brewer, R.D. and Jones, S.E. (2007) Binge Drinking and Associated Health Risk Behaviors among High School Students. Pediatrics, 119, 76-85. http://dx.doi.org/10.1542/peds.2006-1517

[14] Strauch, E.S., Pinheiro, R.T., Silva, R.A. and Horta, B.L. (2009) Alcohol Use among Adolescents: A Population-Based Study. Revista de Saúde Pública, 43, 647-655. http://dx.doi.org/10.1590/S0034-89102009005000044

[15] Stolle, M., Sack, P.M. and Thomasius, R. (2009) Binge Drinking in Childhood and Adolescence: Epidemiology, Consequences and Interventions. Deutsches Ärzteblatt International, 106, 323-328.

[16] National Research Council and Institute of Medicine (2004) Reducing Underage Drinking: A Collective Responsibility. In: Richard, J., Bonnie and O’Connell, M.E., Eds., Committee on Developing a Strategy to Reduce and Prevent Underage Drinking, Board on Children, Youth and Families, Division of Behavioral and Social Sciences and Education, The National Academies Press, Washington DC. http://www.ncbi.nlm.nih.gov/books/NBK37589/pdf/TOC.pdf

[17] Kraus, L., Baumeister, S.E., Pabst, A. and Orth, B. (2009) Association of Average Daily Alcohol Consumption, Binge Drinking and Alcohol-Related Social Problems: Result from the German Epidemiology Surveys of Substance Abuse. Alcohol \& Alcoholism, 44, 314-320. http://dx.doi.org/10.1093/alcalc/agn110

[18] Chun, J. and Chung, I.J. (2013) Gender Differences in Factors Influencing Smoking, Drinking and Their Co-Occurrence among Adolescents in South Korea. Nicotine \& Tobacco Research, 15, 542-551. http://dx.doi.org/10.1093/ntr/nts181v

[19] Poelen, E.P.A., et al. (2007) Drinking by Parents, Siblings and Friends as Predictors of Regular Alcohol Use in Adolescents and Young Adults: A Longitudinal Twin-Family Study. Alcohol and Alcoholism, 42, 362-369. http://dx.doi.org/10.1093/alcalc/agm042

[20] Scholte, R.H.J., et al. (2008) Relative Risks of Adolescent and Young Adult Alcohol Use: The Role of Drinking Fathers, Mothers, Siblings and Friends. Addictive Behaviors, 33, 1-14. http://dx.doi.org/10.1016/j.addbeh.2007.04.015

[21] Donovan, J.E. (2009) Estimated Blood Alcohol Concentrations for Child and Adolescent Drinking and Their Implications for Screening Instruments. Pediatrics, 123, e975-e981. http://dx.doi.org/10.1542/peds.2008-0027

[22] Hingson, R.W., Heeren, T. and Winter, M.R. (2006) Age of Alcohol-Dependence Onset: Associations with Severity of Dependence and Seeking Treatment. Pediatrics, 118, e755-e763. http://dx.doi.org/10.1542/peds.2006-0223

[23] Hingson, R.W., Edwards, E.M., Heeren, T. and Rosenbloom, D. (2009) Age of Drinking Onset and Injuries, Motor Vehicle Crashes and Physical Fights after Drinking and When Not Drinking. Alcoholism: Clinical and Experimental Research, 33, 783-790. http://dx.doi.org/10.1111/j.1530-0277.2009.00896.x

[24] Vinther-Larsen, M., Huckle, T., You, R. and Casswell, S. (2013) Area Level Deprivation and Drinking Patterns among Adolescents. Health \& Place, 19, 53-58. http://dx.doi.org/10.1016/j.healthplace.2012.09.014

[25] Verho, A., Laatikainen, T., Vartiainen, E. and Puska, P. (2012) Changes in Alcohol Behaviour among Adolescents in North-West Russia between 1995 and 2004. Journal of Environmental and Public Health, 2012, Article ID: 736249.

[26] Kokkevi, A., Richardson, C., Olszewski, D., Matias, J., Monshouwer, K. and Bjarnason, T. (2012) Multiple Substance Use and Self-Reported Suicide Attempts by Adolescents in 16 European Countries. European Child \& Adolescent Psychiatry, 21, 443-450. http://dx.doi.org/10.1007/s00787-012-0276-7

[27] Hibell, B., et al. (2009) The 2007 ESPAD Report: Substance use among Students in 35 European Countries. Swedish Council for Information on Alcohol and Other Drugs, Stockholm. http://www.espad.org/Uploads/ESPAD reports/2007/The 2007 ESPAD Report-FULL 091006.pdf 
[28] Arvanitidou, M., et al. (2007) Decreasing Prevalence of Alcohol Consumption among Greek Adolescents. The American Journal of Drug and Alcohol Abuse, 33, 411-417. http://dx.doi.org/10.1080/00952990701315384

[29] Simons-Morton, B.G., et al. (2009) Gender Specific Trends in Alcohol Use: Cross-Cultural Comparisons from 1998 to 2006 in 24 Countries and Regions. International Journal of Public Health, 54, 199-208. http://dx.doi.org/10.1007/s00038-009-5411-y

[30] Melchior, M., Chastang, J.F., Goldberg, P. and Fombonne, E. (2008) High Prevalence Rates of Tobacco, Alcohol and Drug Use in Adolescents and Young Adults in France: Results from the GAZEL Youth Study. Addictive Behaviours, 33, 122-133. http://dx.doi.org/10.1016/j.addbeh.2007.09.009

[31] Johnston, L.D., O’Malley, P.M., Bachman, J.G. and Schulenberg, J.E. (2012) Monitoring the Future National Survey Results on Drug Use, 1975-2011: Volume I, Secondary School Students. Ann Arbor: Institute for Social Research, The University of Michigan. www.monitoringthefuture.org/pubs/monographs/mtf-vol2_2011.pdf

[32] Hingson, R.W. and Zha, W. (2009) Age of Drinking Onset, Alcohol Use Disorders, Frequent Heavy Drinking and Unintentionally Injuring Oneself and Others after Drinking. Pediatrics, 123, 1477-1484. http://dx.doi.org/10.1542/peds.2008-2176

[33] Tsiligianni, et al. (2012) The Association between Alcohol and Tobacco Use among Elementary and High School Students in Crete, Greece. Tobacco Induced Diseases, 10, 15. http://dx.doi.org/10.1186/1617-9625-10-15

[34] FilhoI, V.C.B., de Campos, W. and da Silva Lopes, A. (2012) Prevalence of Alcohol and Tobacco Use among Brazilian Adolescents: A Systematic Review. Revista de Saúde Pública, 46, 901-917. http://dx.doi.org/10.1590/S0034-89102012000500018

[35] Dick, D.M., Pagan, J.L., Viken, R., Purcell, S., Kaprio, J., Pulkkinen, L. and Rose, R.J. (2007) Changing Environmental Influences on Substance Use Across Development. Twin Research and Human Genetics, 10, 315-326. http://dx.doi.org/10.1375/twin.10.2.315

[36] Whiteman, S.D., Jensen, A.C. and Maggs, J.L. (2013) Similarities in Adolescent Siblings' Substance Use: Testing Competing Pathways of Influence. Journal of Studies on Alcohol and Drugs, 74, 104-113.

[37] Bellis, M.A., Phillips-Howard, P.A., Hughes, K., Hughes, S., Cook, P.A., Morleo, M., Hannon, K., Smallthwaite, L. and Jones, L. (2009) Teenage Drinking, Alcohol Availability and Pricing: A Cross-Sectional Study of Risk and Protective Factors for Alcohol-Related Harms in School Children. BMC Public Health, 9, 380. http://dx.doi.org/10.1186/1471-2458-9-380

[38] Graziano, F., Bina, M., Giannotta, F. and Ciairano, S. (2012) Drinking Motives and Alcoholic Beverage Preferences among Italian Adolescents. Journal of Adolescence, 35, 823-831. http://dx.doi.org/10.1016/j.adolescence.2011.11.010

[39] Stewart, S.H. and Devine, H. (2000) Relations between Personality and Drinking Motives in Young Adults. Personality and Individual Differences, 29, 495-511. http://dx.doi.org/10.1016/S0191-8869(99)00210-X

[40] Kuntsche, E., Von Fischer, M. and Gmel, G. (2008) Personality Factors and Alcohol Use: A Mediator Analysis of Drinking Motives. Personality and Individual Differences, 45, 796-800. http://dx.doi.org/10.1016/j.paid.2008.08.009

[41] Schulte, M.T., Ramo, D. and Brown, S.A. (2009) Gender Differences in Factors Influencing Alcohol Use and Drinking Progression among Adolescents. Clinical Psychology Review, 29, 535-547. http://dx.doi.org/10.1016/j.cpr.2009.06.003

[42] Eaton, D.K., Kann, L., Kinchen, S., Shanklin, S., Ross, J., Hawkins, J., et al. (2008) Youth Risk Behavior Surveillance —United States, 2007. Morbidity and Mortality Weekly Report (MMWR), 57, 1-131.

[43] MacArthur, G.J., Smith, M.C., Melotti, R., Heron, J., Macleod, J., Hickman, M., Kipping, R.R., Campbell, R. and Lewis, G. (2012) Patterns of Alcohol Use and Multiple Risk Behaviour by Gender during Early and Late Adolescence: The ALSPAC Cohort. Journal of Public Health, 34, i20-i30. http://dx.doi.org/10.1093/pubmed/fds006

[44] Breslin, F.C. and Adlaf, E.M. (2005) Part-Time Work and Adolescent Heavy Episodic Drinking: The Influence of Family and Community Context. Journal of Studies on Alcohol and Drugs, 66, 784-794.

[45] Karriker-Jaffe, K.J. (2011) Areas of Disadvantage: A Systematic Review of Effects of Area-Level Socioeconomic Status on Substance Use Outcomes. Drug and Alcohol Review, 30, 84-95. http://dx.doi.org/10.1111/j.1465-3362.2010.00191.x

[46] Hibell, B., et al. (2004) The ESPAD Report 2003: Alcohol and Other Drug Use among Students in 35 European Countries. The Swedish Council for Information on Alcohol and Other Drugs (CAN) and the Pompidou Group at the Council of Europe, Stockholm. http://www.espad.org/Uploads/ESPAD_reports/2003/The_2003_ESPAD_report.pdf

[47] WHO (2011) Global Status Report on Alcohol and Health. World Health Organization, Geneva. http://www.who.int/substance_abuse/publications/global_alcohol_report/msbgsruprofil.pdf 
Scientific Research Publishing (SCIRP) is one of the largest Open Access journal publishers. It is currently publishing more than 200 open access, online, peer-reviewed journals covering a wide range of academic disciplines. SCIRP serves the worldwide academic communities and contributes to the progress and application of science with its publication.

Other selected journals from SCIRP are listed as below. Submit your manuscript to us via either submit@scirp.org or Online Submission Portal.
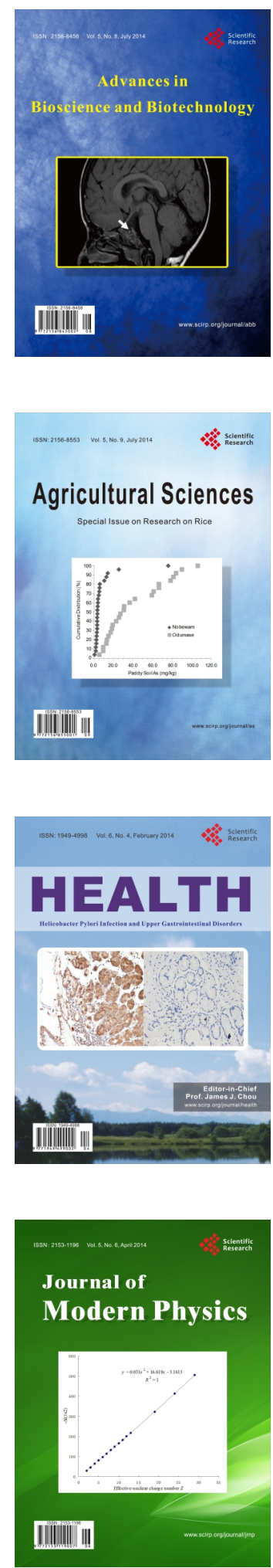
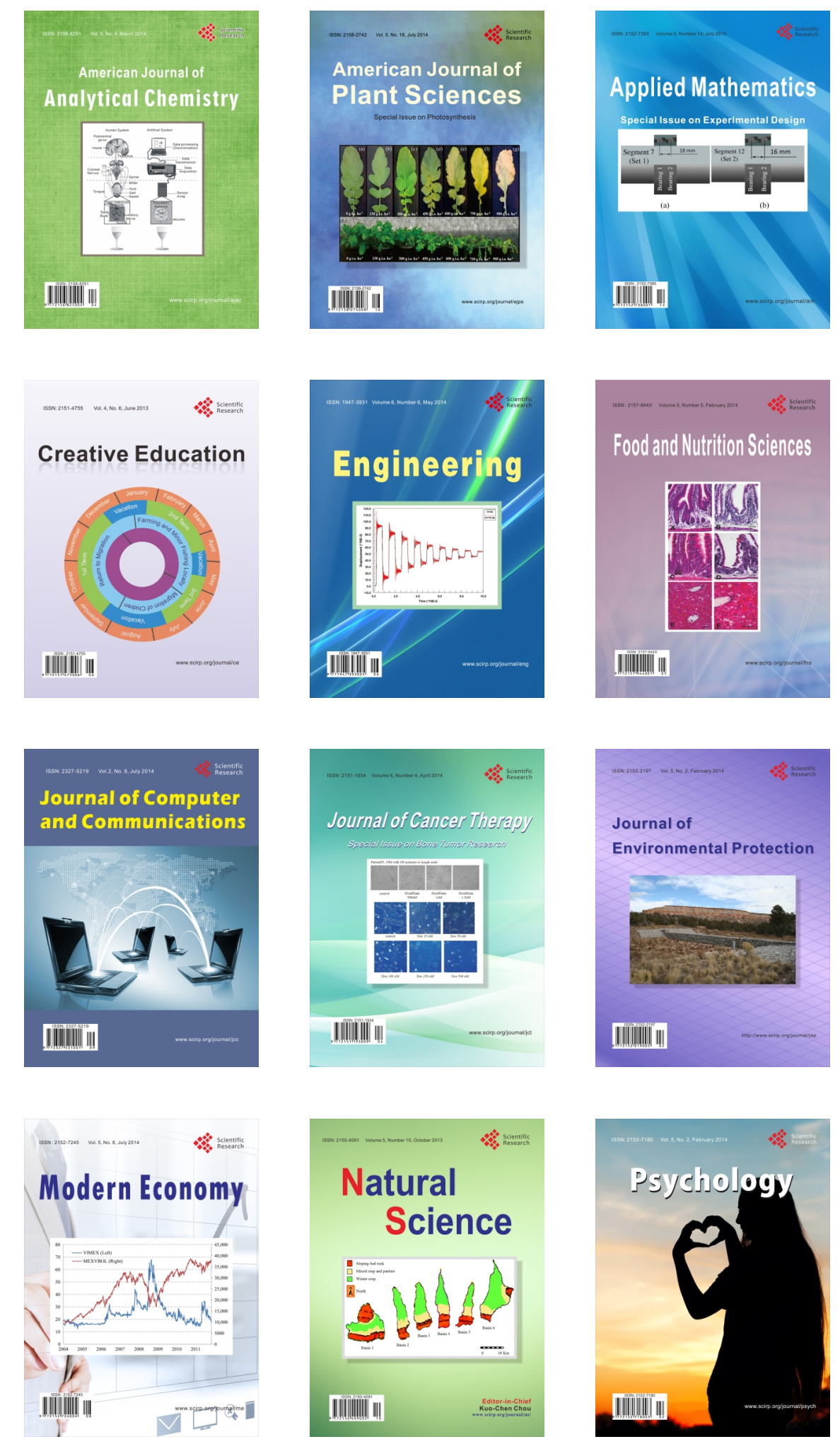